\title{
The Behavior of CPW-Fed Sierpinski Curve Fractal Antenna
}

\author{
Abdelati REHA $^{1}$, Abdelkebir EL AMRI ${ }^{2}$, Marouane BOUCHOUIRBAT ${ }^{1}$ \\ ${ }^{I}$ Department of Electronic Engineering, ISGA MARRAKECH, MOROCCO \\ ${ }^{2}$ RITM Laboratory, ESTC, HASSAN II University, CASABLANCA, MOROCCO \\ abdelati.reha@isga.ma, abdelkebir_elamri@yahoo.fr,marouane.bouchouirbat@isga.ma
}

\begin{abstract}
In this paper, the behavior of Coplanar Waveguide (CPW) fed SIERPINSKI curve fractal antenna is studied. The results show that there is a relationship between the iteration number and the resonance frequencies. With increase in the number of iteration the resonance frequency decreases with a constant ratio. The use of fractal structures to design antennas makes them more miniaturized. The simulated results obtained from CADFEKO a Method of Moments (MoM) model based Solver and measurement using Vector Network Analyzer Anritsu MS2026C are in good agreement.
\end{abstract}

Index Terms - Antenna design, Fractal Antennas, SIERPINSKI Curve.

\section{INTRODUCTION}

With the multiplication and the miniaturization of telecommunication systems and their integration in restricted environments like tablets, smartphones, laptops and other embedded systems. The design of miniaturized antennas with multi-band and broadband behavior becomes a necessity.

Miniaturization techniques are based on geometric manipulation (using fractal geometries, the use of bend forms, varying distance between feeder and short plate, PIFA shape [1]-[5]) or material manipulation (Loading with a high-dielectric material, lumped elements, conductors, capacitors, short plate [6] ), or the combination of two or more techniques [7]. Also several works have appeared in the literature in which the size of the microstrip patch antenna has been reduced by introducing various types of slots in the microstrip patch antenna[8]- [12].

In this paper, we will study the behavior of a CPW-Fed SIERPINSKI Curve fractal antenna designed initially based on the modification of a rectangular patch antenna. The modification of rectangular geometry to the first iteration of SIERPINSKI curve fractal structure, while keeping the same area, allows having a lower resonance frequency. The use of higher iterations allows reducing the resonance frequency with a constant ratio of 0.71 similar or better than for some other works [13][17]. The results are obtained using CADFEKO a MoM Based solver and are validated with measurement using Vector Network Analyzer ANRITSU MS2026C. 


\section{SIERPINSKI FRACTAL GEOMETRIES}

The Polish mathematician SIERPINSKI invented this structure. There are several variants of this geometry among which: SIERPINSKI Triangle (Figure1-a), SIERPINSKI Carpet (Figure 1-b), and SIERPINSKI Curve (Figure1-c).

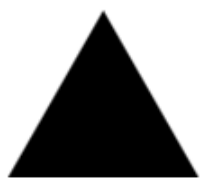

Itération 0

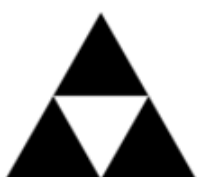

Itération 1

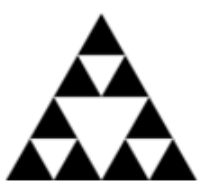

Itération 2

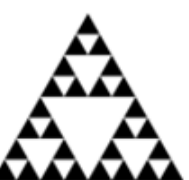

Itération 3

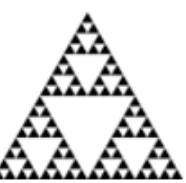

Itération 4

a. SIERPINSKI Triangle

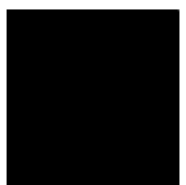

Itération 0

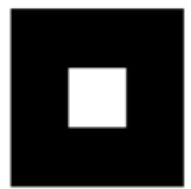

Itération 1

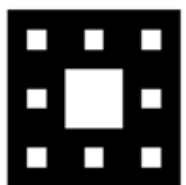

Itération 2

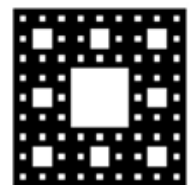

Itération 3

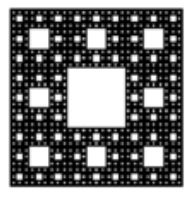

Itération 4

b. SIERPINSKI Carpet

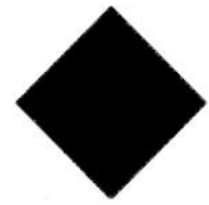

Itération 0

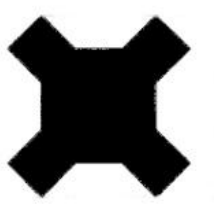

Itération 1

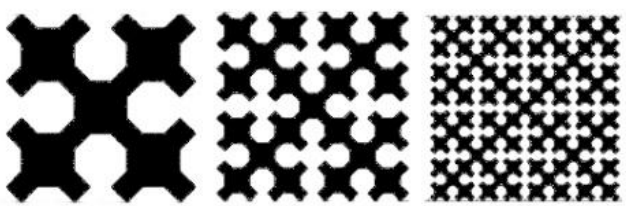

Itération 2
Itération 3

Itération 4

c. SIERPINSKI Curve

Fig.1. The four iterations of the SIERPINSKI fractal structures (a-Triangle, b-Carpet, c-Curve)

The construction of SIERPINSKI Curve structure is made from a lozenge and applying the following steps:

1 - We rotate the diamond at an angle of $\pi / 2$ around its center,

2- We add to the result four copies of a lozenge with 2 as a factor of reduction.

3- We bring together the 5 elements.

4- Between the iteration $i$ and $i+1,5$ copies are generated with 2 as a factor of reduction.

Figure 1-c shows the first four iterations of the SIERPINSKI Curve fractal structure.

The HAUSDORFF dimension of the SIERPINSKI Curve is given by the equation (1) [18]:

$$
d=\frac{\ln (2)}{\ln (\sqrt{2})}=2
$$

\section{ANTENNA DESIGN AND RESULTS}

\section{A. CPW-Fed rectangular patch antenna}

Based on Transmission Lines Method [19], the dimensions of a CPW-fed rectangular patch antenna operating in the frequency $\mathrm{f}_{\mathrm{r}}=2.5 \mathrm{GHz}$ printed on a FR-4 substrate with dielectric constant $\varepsilon_{\mathrm{r}}=4.4$, thickness $\mathrm{h}=1.6 \mathrm{~mm}$ are: $\mathrm{W}_{\mathrm{p}}=36.22 \mathrm{~mm}, \mathrm{~L}_{\mathrm{p}}=28.01 \mathrm{~mm}, \mathrm{~W}_{\mathrm{f}}=2.95 \mathrm{~mm}$ (Figure 2). Figure 5 (red line) shows the $S_{11}$ parameter versus frequencies. 


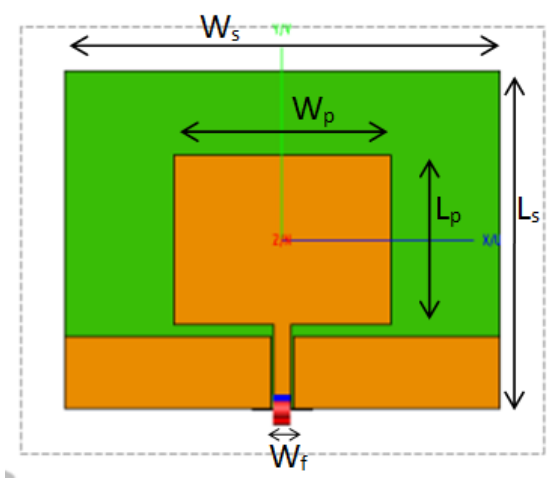

Fig.2. The geometry of rectangular patch antenna fed by CPW

\section{B. Modifying the rectangular geometry using the SIERPINSKI Curve Fractal structure}

To reduce the resonance frequency of a rectangular patch antenna, it is necessary to increase the size of the antenna or increase the permittivity of the substrate[19]. To reduce this frequency without changing the size of the antenna or changing the permittivity of the substrate, several techniques are introduced among which the addition of slots or the use of fractal geometry structures.

The previous rectangular patch antenna fed by CPW (Figure 2) will be modified based on the first iteration of the SIERPINSKI Curve structure to keep the surface of the radiating element almost equal to the surface of the rectangular patch as shown in figure 3. After that, three iterations are studied (Figure 4).

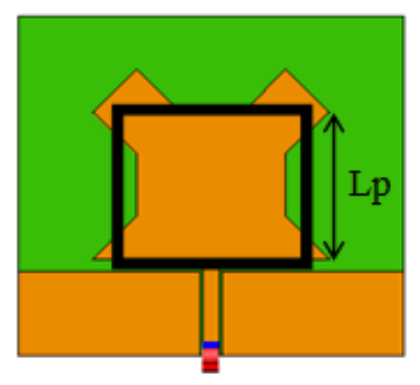

Fig.3. The geometry of the modified antenna ( $1^{\text {st }}$ iteration of the SIERPINSKI Curve)

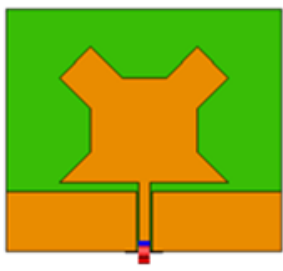

$1^{\text {st }}$ iteration

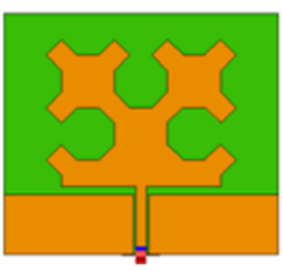

$2^{\text {nd }}$ iteration

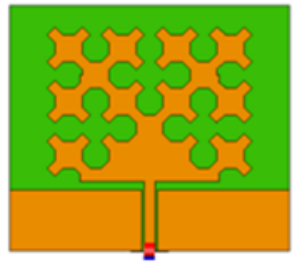

$3^{\text {rd }}$ iteration

Fig.4. Three iterations of CPW-Fed SIERPINSKI curve fractal antenna

The Simulated $S_{11}$ shows that with increase in the number of iteration the resonance frequency decreases and the bandwidth decreases (Figure 5). 


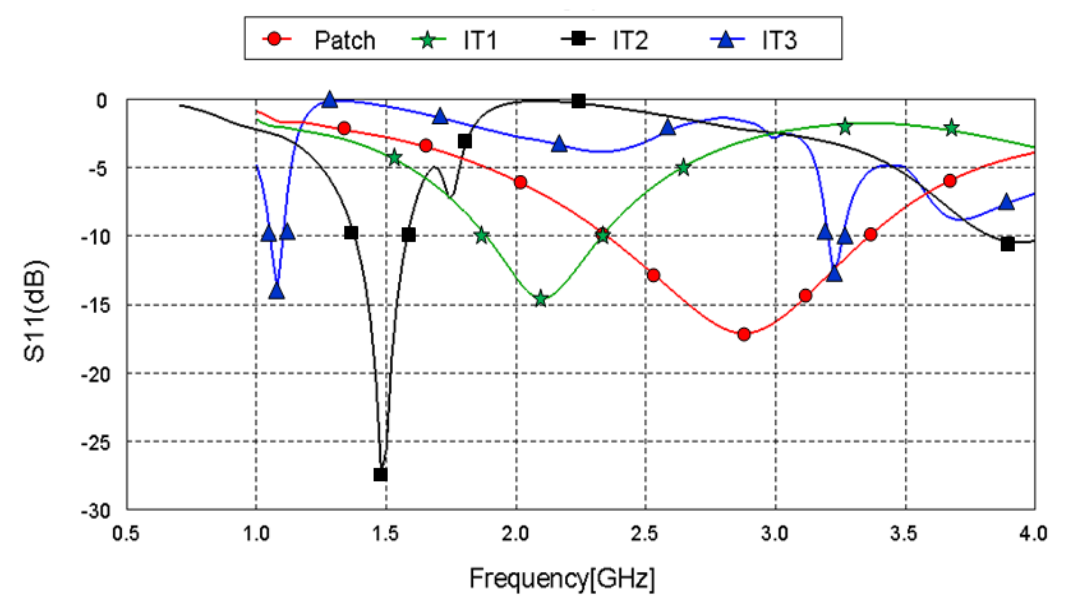

Fig.5. The simulated $\mathrm{S}_{11}$ parameter of the CPW-Fed rectangular patch and the 3 first iterations of the SIERPINSKI Curve fractal antennas

Table I summarizes the different resonance frequencies, bandwidths, maximum gains at the resonance frequencies, and the range of gains in the bandwidths. We note that despite the decrease in resonance frequencies, the antenna loses its ultra-wideband behavior and its gain decreases. We also note that the ratio of resonance frequencies between iteration $i+1$ and $i$ is constant (Formula 2).

$$
\frac{f_{r}\left(\text { iteration }_{i+1}\right)}{\left.f_{r} \text { (iteration }_{i}\right)} \approx 0.71
$$

TABLE I. SUMMARY OF RESULTS

\begin{tabular}{ccccc}
\hline Antenna & $\begin{array}{c}\text { Resonance } \\
\text { frequency } \\
(\mathbf{G H z})\end{array}$ & $\begin{array}{c}\text { Bandwidth } \\
(\mathbf{M H z})\end{array}$ & $\begin{array}{c}\text { Maximum gain in the } \\
\text { resonance frequency } \\
(\mathbf{d B})\end{array}$ & $\begin{array}{c}\text { Gains * } \\
\text { (Min - Max }) \mathbf{~ d B}\end{array}$ \\
\hline Patch & 2.92 & $\begin{array}{c}1030 \\
(2.34-3.37 \mathrm{GHz})\end{array}$ & 1.8 & $1.6-4.3$ \\
Iteration 1 & 2.1 & $\begin{array}{c}470 \\
(1.87-2.34 \mathrm{GHz}) \\
220\end{array}$ & 1.4 & $1.2-1.6$ \\
Iteration 2 & 1.48 & $\begin{array}{c}220 \\
(1.36-1.58 \mathrm{GHz}) \\
60\end{array}$ & 1.3 & 0.3 \\
Iteration 3 & 1.07 & $(1.04-1.1 \mathrm{GHz})$ & 1.1 & 0.3 \\
\hline
\end{tabular}

(*) Gains are given in the $-10 \mathrm{~dB}$ Bandwidths

This result is considered similar or better than for some other works, table II summarizes this comparison.

Figure 6 shows the radiation patterns for the CPW-fed Rectangular patch and the 3 iterations of SIERPINSKI Curve fractal antennas at their resonance frequencies. We observe that the gain pattern is omnidirectional and stable.

The behavior of the resonance frequencies when we change the iteration number has been tested for the antennas with other dimensions $\left(\mathrm{W}_{\mathrm{s}}=18.25 \mathrm{~mm}\right.$ and $\left.\mathrm{L}_{\mathrm{s}}=13.76 \mathrm{~mm}\right)$. Figure 7 shows the variation of $\mathrm{S}_{11}$ parameters versus iterations numbers. We confirm that the formula 2 is respected even if we change the antennas dimensions. 
TABLE II. COMPARISON WITH SOME OTHER WORKS

\begin{tabular}{|c|c|}
\hline Antennas & Rate of reduction $\frac{\left.f_{r} \text { (iteration } i+1\right)}{\left.f_{r} \text { (iteration }{ }_{i}\right)}$ for the first resonance frequency \\
\hline$[\mathbf{1 3}]$ & $\approx 0.87$ \\
\hline$[\mathbf{1 4}]$ & $\approx 0.72$ \\
\hline$[\mathbf{1 5}]$ & Antenna $\approx 0.7 \quad$ Antenna $2 \approx 0.8$ \\
\hline$[\mathbf{1 6}]$ & 8 configuration $:$ from 0.76 to 0.99 \\
\hline$[\mathbf{1 7}]$ & $\approx 0.58$ \\
\hline Our work & $\approx 0.71$ \\
\hline
\end{tabular}

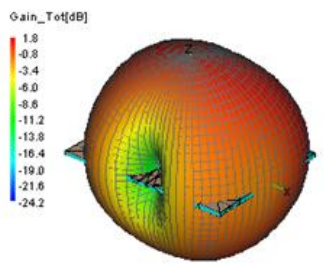

(a) Patch $(\mathrm{f}=2.92 \mathrm{GHz})$

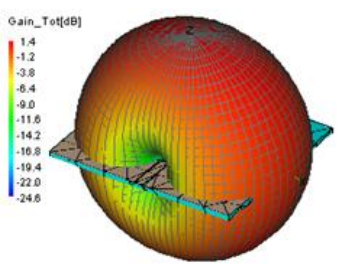

(b) Iteration $1\left(\mathrm{f}_{\mathrm{r}}=2.1 \mathrm{GHz}\right)$

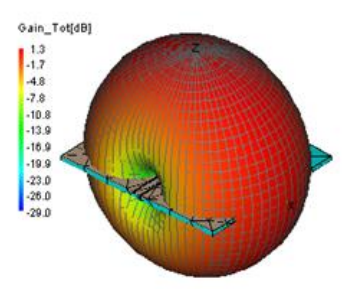

(c) Iteration $2(\mathrm{Fr}=1.48 \mathrm{GHz})$

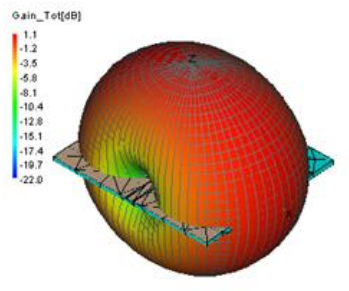

(d) Iteration $3(\mathrm{f}=1.07 \mathrm{GHz})$

Fig.6. Radiation pattern for the CPW-fed Rectangular patch and the 3 iterations of SIERPINSKI Curve fractal antennas at their resonance frequencies.

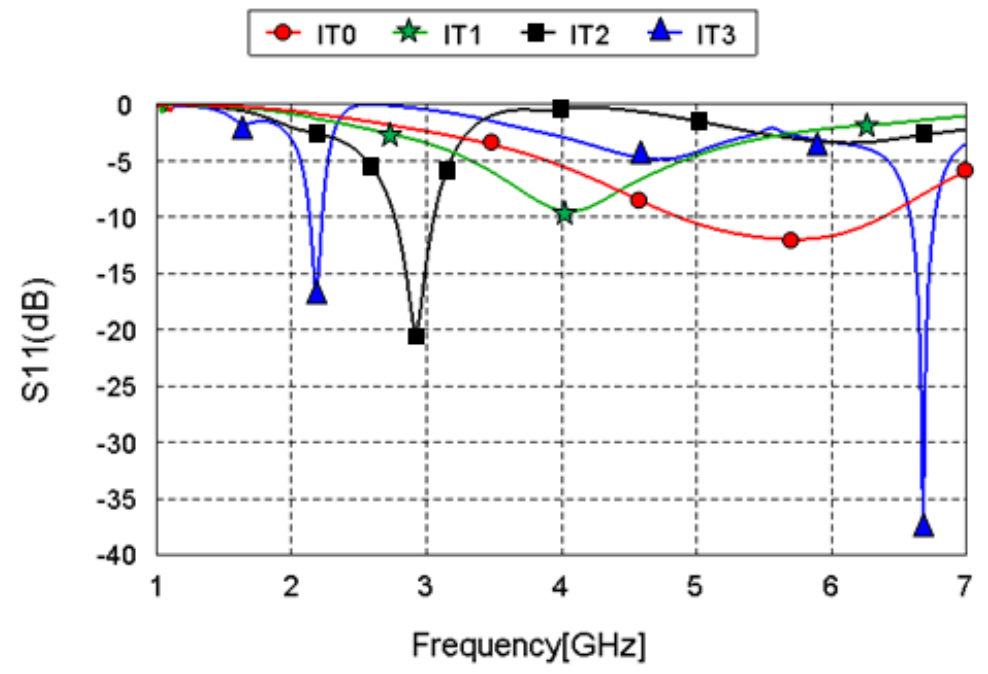

Fig.7. The simulated $S_{11}$ parameter of the CPW-Fed rectangular patch and the 3 first iterations of the SIERPINSKI Curve Fractal antennas $(\mathrm{Ws}=18.25 \mathrm{~mm}$ and $\mathrm{Ls}=13.76)$

\section{Realization and measurements}

Figure 8 shows the manufactured CPW-Fed rectangular patch and the three first iterations of the SIERPINSKI Curve fractal antennas. The antennas are printed on a FR-4 substrate with dielectric constant $\varepsilon_{\mathrm{r}}=4.4$, thickness $\mathrm{h}=1.6 \mathrm{~mm}$, with $\mathrm{W}_{\mathrm{s}}=36.22 \mathrm{~mm}$ and $\mathrm{L}_{\mathrm{s}}=28.01 \mathrm{~mm}$. The $\mathrm{S}_{11}$ parameters measurements were performed with ANRITSU MS2026C Vector Network Analyzer. Figure 9 shows the comparison between $S_{11}$ simulated and measured. We note that there is an agreement between the simulated and measured results even if there are some differences that are due to the manufacturing process. 


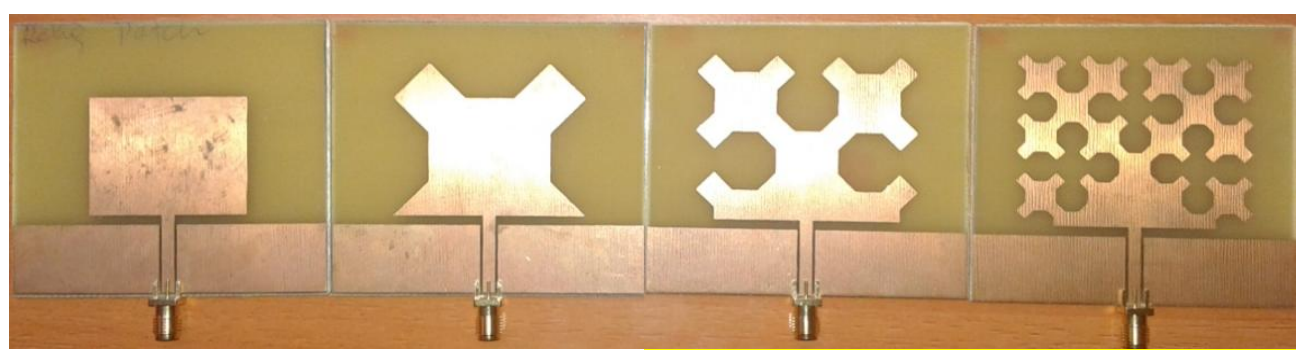

Fig.8. Prototypes of studied antennas
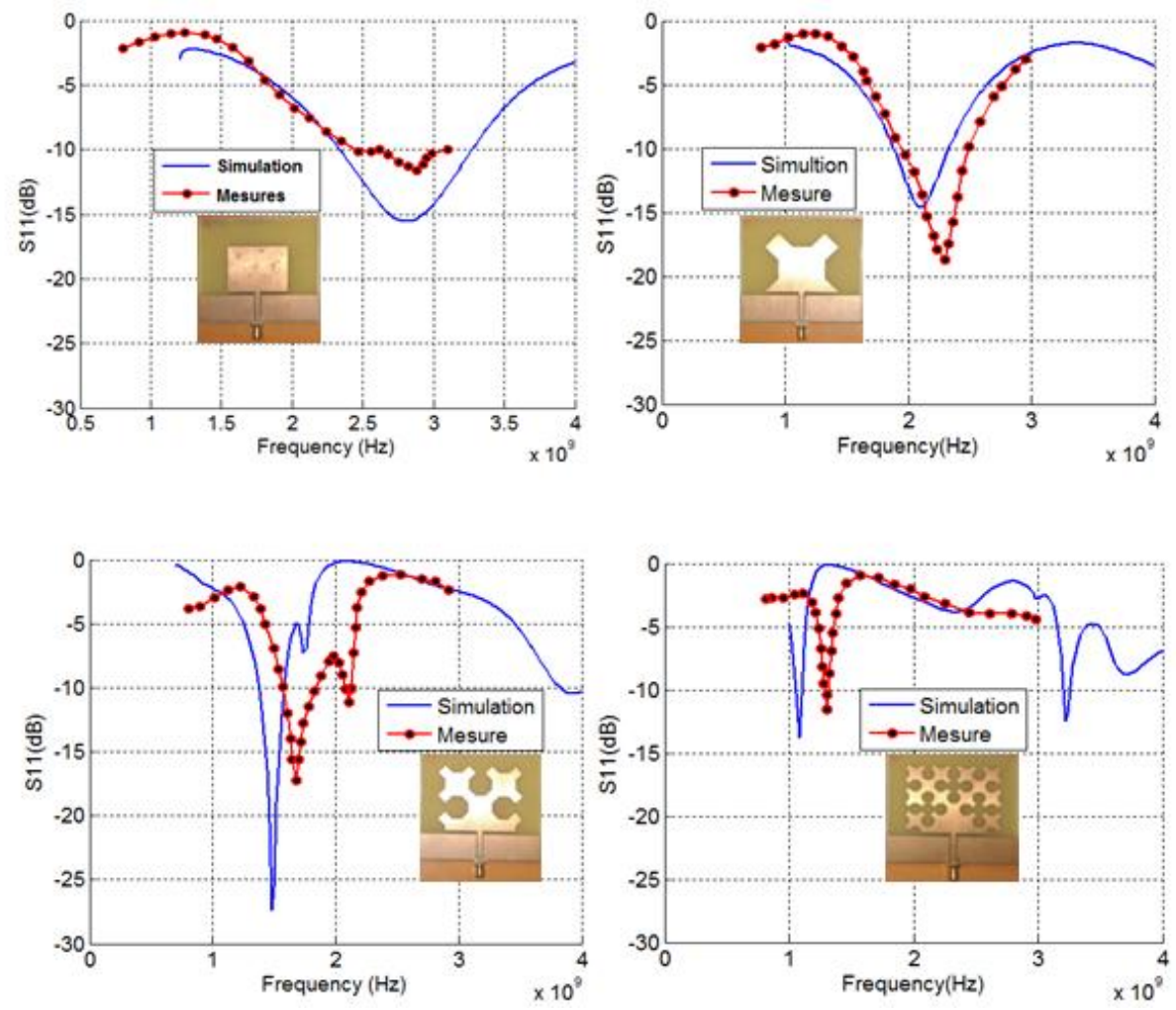

Fig.9. the comparison between $S_{11}$ simulated and measured.

\section{CONCLUSION}

The behavior of CPW-Fed SIERPINSKI Curve fractal antenna was studied. Both simulation and measurement results prove that there is a relationship between the iteration number and the first resonance frequency. In fact, with increase in the number of iteration the resonance frequency decreases with a constant ratio of 0.71 , but the maximum gain and the bandwidth decreases.

The use of fractal geometries is one of the best solutions to design braodband and multiband antennas. Also, it is one of the techniques used for the antenna miniaturization. Indeed, to reduce the CPW-fed rectangular patch antenna resonance frequency, we need to increase its dimensions or increase the relative permittivity of its substrate. But, by the modification of its geometry using SIERPINSKI Curve Fractal structure we can design an antenna with smaller resonance frequencies when the iteration number increases. Also, we can predict the resonance frequency while the reduction ration of the first resonance frequency is similar. 
As perspective of this work, other parametric studies should be done such as the variation of the relative permittivity in order to get a complete idea about the behavior of CPW-Fed SIERPINSKI Curve Fractal Antenna.

\section{REFERENCES}

[1] M. T. Yassen, M. R. Hussan, H. A. Hammas, and A. J. Salim, "Design of Compact Dual-band Fractal Monopole Antenna with Virtually Extended Ground Plane," Adv. Electromagn., vol. 2018.

[2] Hong-Twu Chen, Kin-Lu Wong, and Tzung-Wern Chiou, "PIFA with a meandered and folded patch for the dual-band mobile phone application,” IEEE Trans. Antennas Propag., vol. 51, no. 9, pp. 2468-2471, Sep. 2003.

[3] A. Reha, A. El Amri, O. Benhmammouch, and A. Oulad Said, "Fractal Antennas : A Novel Miniaturization Technique for wireless Networks," Trans. Netw. Commun., vol. 2, no. 5, Oct. 2014.

[4] S. Sun and L. Zhu, "Miniaturised patch hybrid couplers using asymmetrically loaded cross slots," IET Microw. Antennas Propag., vol. 4, no. 9, p. 1427, 2010.

[5] P.-L. Chi, R. Waterhouse, and T. Itoh, "Antenna Miniaturization Using Slow Wave Enhancement Factor from Loaded Transmission Line Models,” IEEE Trans. Antennas Propag., vol. 59, no. 1, pp. 48-57, Jan. 2011.

[6] A. K. Skrivervik, J.-F. Zurcher, O. Staub, and J. R. Mosig, "PCS antenna design: the challenge of miniaturization," IEEE Antennas Propag. Mag., vol. 43, no. 4, pp. 12-27, Aug. 2001.

[7] M. Tarbouch, "Trial of H-Tree fractal slots in the ground plane of a micropstrip patch antenna," Int. J. Microw. Opt. Technol., vol. 13, no. 1, pp. 51-60, Jan. 2018.

[8] C. G. Kakoyiannis and P. Constantinou, "A compact microstrip antenna with tapered peripheral slits for CubeSat RF Payloads at 436MHz: Miniaturization techniques, design \&\#x00026; numerical results,”2008, pp. 255-259.

[9] J. Anguera, L. Boada, C. Puente, C. Borja, and J. Soler, "Stacked H-Shaped Microstrip Patch Antenna," IEEE Trans. Antennas Propag., vol. 52, no. 4, pp. 983-993, Apr. 2004.

[10] S. A. Bokhari, J.-F. Zurcher, J. R. Mosig, and F. E. Gardiol, "A small microstrip patch antenna with a convenient tuning option," IEEE Trans. Antennas Propag., vol. 44, no. 11, pp. 1521-1528, Nov. 1996.

[11] S. Chatterjee, U. Chakraborty, I. Sarkar, P. P. Sarkar, and S. K. Chowdhury, "A compact microstrip antenna for mobile communication," 2010, pp. 1-3.

[12] Wen-Shyang Chen, Chun-Kun Wu, and Kin-Lu Wong, "Square-ring microstrip antenna with a cross strip for compact circular polarization operation," IEEE Trans. Antennas Propag., vol. 47, no. 10, pp. 1566-1568, Oct. 1999.

[13] M. Tarbouch, A. El Amri, H. Terchoune, and O. Barrou, "A compact microstrip patch antenna based on fractal geometry on the ground plane," 2018, pp. 1-8.

[14] M. Tarbouch, A. El Amri, and H. Terchoune, "Design, Realization and Measurements of Compact CPW-Fed Microstrip Octagonal Patch Antenna with H Slot for WLAN and WIMAX Applications," Int. J. Microw. Opt. Technol., vol. 12, no. 5, pp. 389-398, Sep. 2017.

[15] D.-C. Chang, B.-H. Zeng, and J.-C. Liu, "CPW-Fed Circular Fractal Slot Antenna Design for Dual-Band Applications," IEEE Trans. Antennas Propag., vol. 56, no. 12, pp. 3630-3636, Dec. 2008.

[16] K. J. Vinoy, J. K. Abraham, and V. K. Varadan, "On the relationship between fractal dimension and the performance of multi-resonant dipole antennas using koch curves," IEEE Trans. Antennas Propag., vol. 51, no. 9, pp. 2296-2303, Sep. 2003.

[17] N. Sharma, G. P. Singh, and V. Sharma, "Miniaturization of fractal antenna using novel Giuseppe peano geometry for wireless applications," 2016, pp. 1-4.

[18] H. Sagan, Space-filling curves. New York (NY): Springer, 1994.

[19] C. A. Balanis, Antenna theory: analysis and design, 3rd ed. Hoboken, NJ: John Wiley, 2005. 